to have lens opacity at operation, others after operation, but there is no evidence that the operation can be held responsible. In some, as would be expected, lens opacity appeared some years after a successful trephine operation in an elderly patient. In some of the cases that did not do well cataract developed, suggesting that an imperfect or unsuccessful operation was much more likely to be followed by cataract than a successful one.

The results of extraction of the lens after a trephine operation do not seem successful as far as vision goes. There are only three or four isolated cases and in all these vision was poor after the extraction, successful though the operation was. At the same time vision was not good before the cataract developed-as far as the records can show.

This paper is the outcome of part of my work as Moorfields Research Scholar, and I have had free use of all the patients' records.

For such facilities and for permission to publish the results I am indebted to the surgical staff whom I wish tc thank.

\title{
ON THE VISIBILITY OF THE NUCLEI OF THE ENDOTHELIAL CELLS OF THE CORNEA IN MAN
}

BY

\author{
T. HARRISON BUTLER \\ BIRMINGHAM
}

THE nuclei of the endothelial cells are easily seen in the eye of the pig, but it is generally held that they are invisible in the human cornea.

I have just examined an engineer, aged 51 years, who in his younger days had been a miner. His endothelial cells were unusually large and I was astonished to find that the nuclei were perfectly visible. Using ocular 2 and objective A3, a magnification of 35 , the cells were seen to be hexagonal and in the centre of each there was a dark dot. This did not alter in appearance with any modification of the focus and was not therefore an optical effect. The appearance was exactly similar to that seen in the pig's eye and I have no doubt that I was looking at the nuclei. I immediately with the same optical system examined another normal patient and was quite unable to see the nuclei and also confirmed the observation that the miner's cells were abnormally large. The nuclei were visible in both corneae. 